\title{
The Timing of Signaling: Study in High School or in College?
}

\author{
Sanghoon Conan Lee*
}

December 8, 2005

\begin{abstract}
American students study harder in college than in high school while East Asian students study harder in high school than in college. This paper proposes a signaling explanation for this puzzle and provides its empirical evidence. The theory has three components. First, signaling may occur over time both in high school and college. Second, societies may differ when the signaling takes place, and students work harder in the signaling stage determined by the society as a whole. Third, the signaling stage is more likely to be high school if alumni network is more important for job performances. A testable implication of the theory is that high ability workers in East Asia are relatively more concentrated among a few top colleges as compared with their US counterparts. This implication is confirmed by college distribution data on largest firm CEOs in US and Korea.
\end{abstract}

Keywords: Education, Signaling, Many Signals, Education Production, International Comparison.

JEL Classification: I21, I28, J22, J24.

*Address: Sauder School of Business, University of British Columbia, 2053 Main Mall, Vancouver, BC, Canada V6T 1Z2; E-mail: sanghoon.lee@sauder.ubc.ca. I am deeply indebted to Thomas Holmes for the encouragement and guidance. I also thank Andrea Moro, Zvi Eckstein, Samuel Kortum, James Schmitz, Hwikwon Ham, Oksana Leukhina, Sunghwan Kim, Alice Schoonbroodt, and participants at applied microeconomics workshop and midwest economic theory conference for valuable comments. Any remaining errors are mine. 


\section{Introduction}

American high school students study substantially less than their East Asian counterparts and there is less pressure in high school. In East Asia it is not rare to see high school students staying in school from 7:30 am to 12:00 am every day. Some students even commit suicide because of their falling grades. ${ }^{1}$ Obviously the pressure also exists in US high schools, but it is not of this magnitude. Time-use surveys show that average American high school students study 4.6 hours per week outside class while Korean and Japanese students study 14 and 19 hours respectively (American Time Use Survey, 2003; Korean Time Use Survey, 2004; Juster and Stafford, 1991).

However, things are reversed in colleges. American students start working diligently and East Asian students stop working. Time-use surveys show that American students study 9.4 hours per week outside class while Korean and Japanese students study only 5.1 and 8.8 hours respectively (American Time Use Survey, 2003; Korean Time Use Survey, 2004; Juster and Stafford, 1991). American college students more than double their study time while East Asian college students study only half as much as they did in high school.

Why do American students study more in college than in high school while East Asian students study more in high school than in college? This paper proposes a signaling explanation for this puzzle. It builds on the ideas of Spence (1973). The main point of departure is that signalling can take place over time both in high school and in college, and that societies may differ in when the signaling takes place. Students work harder in the signaling stage determined by the society as a whole.

I build a two-stage-signaling model and show that there exist two equilibria. In one equilibrium, signaling takes place in high school and students work harder in high school than in college. In

\footnotetext{
${ }^{1}$ The high pressure in East Asian high school has been reported many times by the news media. For example, refer to Elliot (1999), BBC (2000), and Gluck (2001).
} 
this equilibrium, firms believe that college names signal workers' abilities better than college GPAs and this makes students study harder in high school; college names actually become better signals of workers' abilities as workers compete harder to enter better colleges. In the other equilibrium, signaling takes place in college and students work harder in college than in high school. Firms believe that college GPAs signal workers' abilities better than college names and this makes students study harder in college; college GPAs actually become better signals of workers' abilities as workers compete harder to achieve better GPAs.

My model generates two different kinds of explanations for why societies might have different signaling stages. The first explanation is a multiple-equilibria argument. My model shows that the two equilibria with different signaling stages coexist under certain conditions. Thus, two societies with identical fundamentals can have different signaling stages and the signaling stage is selected only by the society's self-fulfilling belief. The second explanation is based on the differences in fundamentals between societies. The model shows that signaling is more likely to take place in high school if college-allumni network is more important for job performances. A case can be made that these conditions are more true for East Asian countries.

The theory also delivers a testable implication I can examine with data. If college names are better signals of workers' abilities in East Asia than in US, high-ability workers in East Asia have to be more concentrated among a few top colleges than their counterparts in US. I examine this implication by looking at college distribution of largest firm CEOs in US and Korea. These top CEOs are clearly high ability workers, and I find that the CEOs in Korea are substantially more concentrated among a few top colleges than the CEOs in US. For example, 44 percent of the Korean CEOs are from Seoul National University which accounts for just .3 percentage of all college students. In contrast, a group of top US colleges, which account for the same percentage of college graduates, have only 18 percent of the US CEOs. 
My theory has implications for two important issues. The first issue concerns the debate over the causes of the mediocre performance of American high school students. It is a well documented fact that the high school performance of American students is not as good as that of their East Asian counterparts. For example, in a recent OECD study, American 15 year olds were ranked 14th in science while Koreans ranked 1st and Japanese 2nd (The Programme for International Student Assessment (PISA), 2000). While many factors may contribute to the mediocre performance of American students, undoubtedly one part of the explanation is simply that American high school students are not studying as hard as their East Asian counterparts.

My theory implies a trade-off between high school and college education performance, the levels of performance depending on when signaling takes place. If signaling were to occur in high school as in East Asia, US students would work more in high school and their high school performance would improve, but they would work less in college and their college performance would decline. The mediocre performance of US high school education may then not be as bad as it looks, for it is one of the reasons that make US higher education performance so exceptional.

The second issue concerns empirical literature estimating education productivity, that use international test data for high school students (e,g. Heyneman and Loxley, 1983; Woessmann, 2000; Hanushek and Luke, 2001). These studies compare the productivity of educational systems across countries. Any productivity study needs to control for all inputs, and in education one input is clearly how hard students are studying. However, any differences in signaling stage leads to differences in study time and this would bias estimates if not properly controlled. For example, these studies conclude that public education expenditure does not matter much for high school students performance. Part of what drives this result is that most East Asian countries belong to low spending group and their high school students do so well. If their excellent performance is at least partly due to signaling occurring in high school, the coefficient for education expenditure will 
be underestimated.

There is huge signaling literature following the seminal work of Spence (1973), generalized in many ways including signaling with many signals (e.g., Quinzii and Rochet, 1985; Engers, 1987; Cho and Sobel, 1990) and repeated signaling (e.g., Cho, 1993; Milgrom and Roberts, 1982; Ayça Kaya, 2005). This paper differs from the previous literature in that there is group externality in signaling: you have to signal your ability in the signaling stage determined by the society as a whole when others also try to signal their abilities. For example, good GPAs in college would not signal your ability if other students and firms do not care about college GPAs.

The rest of paper proceeds as follows. Section 2 presents the model. Section 3 characterizes equilibrium in colleges. Section 4 characterizes equilibrium in high school and find conditions under which each equilibrium exists. Section 5 presents a simulation result. Section 6 provides empirical evidence. Section 7 concludes.

\section{The Model}

In this section I present the model of workers signaling their abilities both in high school and college. Each worker decides how much to study in each school and which college to attend. There are three ability types of workers and two colleges, and this provides a minimal setting where signaling can take place both in high school and in college. Studying does not improve workers' productivity

as usually assumed in signaling literature, but there is networking effect in colleges that makes workers more productive by a fraction $\alpha$ of average student ability in the college. The networking effect coefficient $\alpha$ is the key parameter of the model deciding which type of equilibrium exists. 


\subsection{Workers}

Workers differ in two characteristics: innate ability and disutility of studying in high school. There are three ability types represented by $\theta^{H}, \theta^{M}, \theta^{L}$ where $\theta^{H}>\theta^{M}>\theta^{L}>0$, and each ability type consists of a unit measure of workers. Workers are also heterogeneous in disutility of studying in high school. The disutility coefficient $\gamma$ is distributed, identically across all ability types, subject to the strictly increasing continuous cumulative distribution function $F:[\underline{\gamma}, \bar{\gamma}] \rightarrow[0,1]$.

Each worker goes to high school and college, and the following utility function describes their preferences.

$$
U_{\gamma}\left(n_{h}, n_{c}, w\right) \equiv \gamma \cdot v\left(n_{h}\right)+v\left(n_{c}\right)+w \text { for all } \gamma \in[\underline{\gamma}, \bar{\gamma}] \text { and } n_{h}, n_{c}, w \in \mathbb{R}_{+}
$$

where $w$ is wage, and $n_{h}$ and $n_{c}$ are the time spent studying in high school and college respectively. The study disutility function $v: \mathbb{R}_{+} \rightarrow \mathbb{R}_{-}$is twice differentiable, strictly decreasing, strictly concave, and satisfies the properties that $\lim _{n \rightarrow 1} v(n)=-\infty$ and $v(n)=-\infty$ for $n \geq 1$. This property implies that no workers study more than a unit measure of time either in high school or in college.

Study disutility increases in $\gamma$ even with the same study time. The heterogeneity in $\gamma$ captures variances among students other than their innate abilities. For example, disutility coefficient $\gamma$ would be high for those who just hate studying or those who do not have good education environments. In this model, the heterogeneity in $\gamma$ interferes with effective sorting in high school and allows an equilibrium where some high ability workers end up in a bad college. I assume for simplicity that there is no heterogeneity in disutility of studying in college. 


\subsection{Stage 1: High School}

Each worker decides how much time to spend studying in high school. High school performance $p_{h}$ depends on workers' ability and study time. For simplicity I assume a linear performance function.

$$
p_{h}\left(n_{h}, \theta\right)=\theta n_{h} \text { for all } \theta \text { and } n_{h} \in \mathbb{R}_{+} .
$$

\subsection{Stage 2: Colleges}

There are two colleges - A and B. Each college admits one and half unit measure of workers, using a cut-off rule based on workers' high school performances. ${ }^{2}$ College A and B are ex ante identical, but ex post different in terms of student ability distribution. Without the loss of generality I assume that college A is the superior college which has the better average student ability in equilibrium.

Each worker applies for either college A or college B. Every worker ends up in one of the colleges because the total measure of admission from both colleges is equal to that of all workers. Once in college, workers decide how much time to spend studying. The college performance $p_{c}$ is determined in the same manner as in high school.

$$
p_{c}\left(n_{c}, \theta\right)=\theta n_{c} \text { for all } \theta, n_{h} \in \mathbb{R}_{+} .
$$

There is networking effect in college: job productivity of workers grows by $\alpha$ fraction of the average student ability in their colleges. In other words, job productivity of a college $s$ student increases by $\alpha E(\theta \mid s)(s=A, B)$. College friends at work can help each other improving their job productivity. Moreover, one's job productivity increases even more if his or her friends have better abilities. In this model the networking effect coefficient $\alpha$ is the key parameter that decides which

\footnotetext{
${ }^{2}$ This cut-off rule turns out to be the optimal strategy for each college maximizing its average students ability subject to the requirement that each college has to fill up their seats.
} 
type of equilibrium exists.

\subsection{Stage 3: Job Market}

There are two firms (or more), indexed by 1 and 2, which maximize their expected profits. Both firms have the same constant returns to scale technology where job productivity of a worker is given by his innate ability plus the network productivity gain in college. Thus, a college $s$ graduate with ability $\theta^{i}$ produces $\theta^{i}+\alpha E(\theta \mid s)(s=A, B$ and $i=H, M, L)$.

Firms compete for workers by simultaneously announcing their wage offers. Firms can observe workers' high school performance, college name, and college performance. However, in the equilibria I focus on, workers' high school performances can be perfectly inferred from their college names and thus firms ignore their high school performances. Therefore, firms' wage offers will depend only on college name and college performance.

\subsection{Equilibrium}

A Bayesian Nash Equilibrium of the model consists of the list including each worker's study time and college choice, each college's cut-off level of high school performance for admission and each firm's wage schedule, such that every player's strategy is the best response to the other players' strategies and the firms' beliefs are updated by the Bayesian rule whenever applicable. I focus on the following two types of equilibria in order to show the differences in signaling stage and their impact on study hour and education performance.

Definition 1 Asian equilibrium is a separating Bayesian Nash equilibrium, where college A has only high and medium ability workers and college B has only medium and low ability workers.

Definition 2 US equilibrium is a separating Bayesian Nash equilibrium, where each college has all three ability types of workers. 
There are three points that are noteworthy in the equilibrium definitions. First, a college name is a better signal of a worker's ability in Asian equilibrium. In Asian equilibrium, firms can safely infer that college A graduates are at least of medium ability and that college B graduates are at best of medium ability. Second, specific shares of ability types within colleges do not matter. What matters is whether certain ability types exist with positive measure or not. I use the standard Spence signaling model to analyze equilibrium outcomes in colleges, and it is a typical feature of the Spence model that separating equilibrium outcomes are completely unaffected by the share of each ability types. Third, colleges A and B in US equilibrium do not have to be identical. They may differ in their share of each ability type as long as each college has positive measure of workers of each ability type.

I characterize equilibrium by going backward from the last stage. In the job market, firms make wage offers based on workers' college name and college performance. The standard argument shows that in Bertrand competition for workers both firms will offer the same wage equal to workers' expected productivity.

Lemma 1 Let $w_{i}\left(s, p_{c}\right):\{A, B\} \times \mathbb{R}_{+} \rightarrow \mathbb{R}_{+}$be the equilibrium wage offer function of the firm $i(i=1,2)$. Whenever there exists a positive measure of the workers who attend college $s^{*}$ and perform $p_{c}^{*}$ in college, the wage profile $w_{1}$ and $w_{2}$ satisfy

$$
w\left(s^{*}, p_{c}^{*}\right) \equiv w_{1}\left(s^{*}, p_{c}^{*}\right)=w_{2}\left(s^{*}, p_{c}^{*}\right)=E\left(\theta \mid s^{*}, p_{c}^{*}\right)+\alpha E\left(\theta \mid s^{*}\right) .
$$

Proof. All proofs are in the Appendix.

Lemma 1 implies that every worker, in both Asian and US equilibrium, will be paid his or her true productivity because both of the equilibria are separating equilibria. 


\section{Colleges}

In this section, I characterize college equilibrium outcomes. I show the following two results. First, college students in US equilibrium work harder than their counterparts in Asian equilibrium. Second, the benefit of attending the better college (A) is greater in Asian equilibrium than in US equilibrium. The greater benefit of attending college A in Asian equilibrium later leads students in Asian equilibrium to study harder in high school.

I use the standard results from the Spence model to study signaling in colleges. The following lemma shows that the "single crossing" property holds between college performance and wage.

Lemma 2 (Single Crossing Property)

$$
\frac{\partial}{\partial \theta}\left(\frac{\partial \hat{U} / \partial p_{c}}{\partial \hat{U} / \partial w}\right)>0
$$

where $\hat{U}\left(\theta, p_{c}, w\right) \equiv v\left(p_{c} / \theta\right)+w$ is subutility function after high school.

Figure 1 illustrates a simple application of the Spence signaling model to a hypothetical college $s$ where there exist only high and low ability workers. The single crossing property requires that the indifference curve of low ability workers is steeper than that of high ability workers wherever the two curves intersect. In any separating equilibrium, the lowest ability workers do not study at all and get paid the wage equal to their true productivity. High ability workers can signal themselves away from low ability workers by attaining the performance level $P^{H}$ because the performance level is not profitable for low ability workers to imitate.

However, the separating performance of high ability workers is not unique. In Figure 1 any performance between $\underline{P}^{H}$ and $\bar{P}^{H}$ can be supported as a separating equilibrium performance of high ability workers, with a suitable wage offer curve. Therefore, in order to obtain a unique 


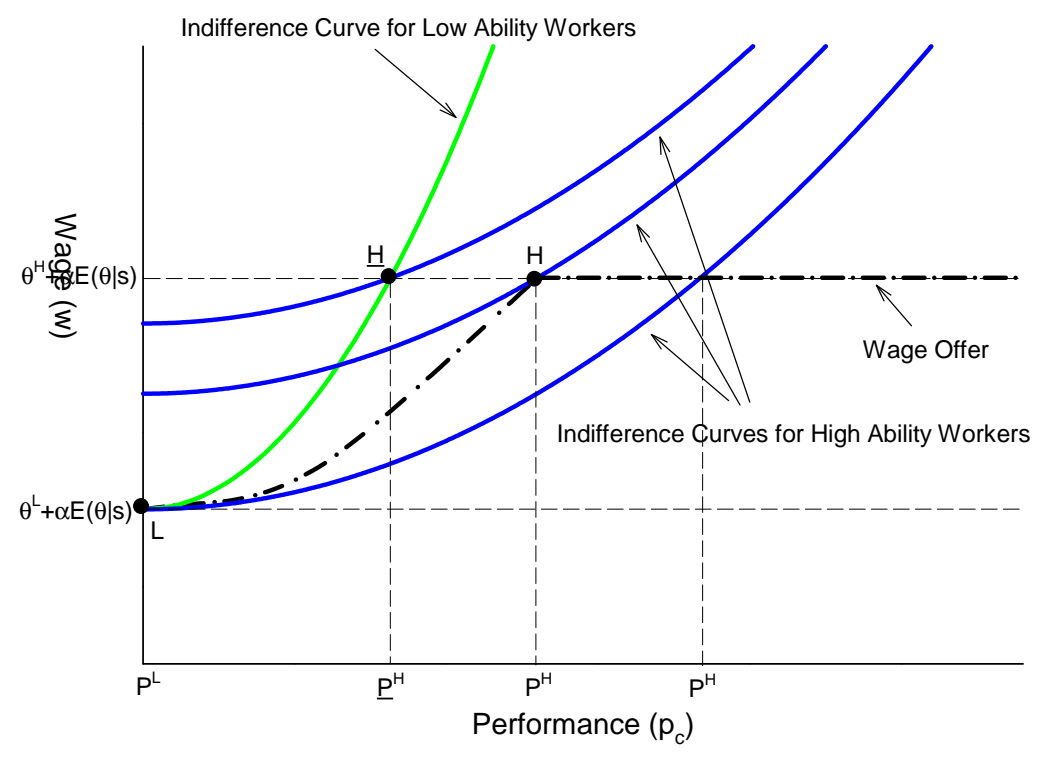

Figure 1: Spence Signaling Model

prediction, I focus on the well known "Riley outcome". The Riley outcome is the unique Paretodominant separating equilibrium from the Spence signaling model. It is also the only equilibrium that survives the refinement of D1 criterion (See Banks and Sobel(1987), Cho and Kreps(1987), and Cho and Sobel (1990)). In this paper I use an equivalent but more practical definition.

Definition 3 Riley outcome is the unique separating equilibrium where the lowest ability workers in each college do not study at all, and the higher ability workers study just enough to achieve the minimum level of performance needed to weakly signal themselves away from the lower ability workers.

For example, in Figure 1 the performance levels $P^{L}$ and $\underline{P}^{H}$ are the Riley outcomes for low and high ability workers respectively. Low ability workers do not work at all $\left(P^{L}=0\right)$, and $\underline{P}^{H}$ is determined so that low ability workers are indifferent between their equilibrium outcome 
$L \equiv\left(P^{L}, \theta^{L}+\alpha E(\theta \mid s)\right)$ and high ability workers' outcome $\underline{H} \equiv\left(\underline{P}^{H}, \theta^{H}+\alpha E(\theta \mid s)\right)$ in Figure 1.

$$
v\left(P^{H} / \theta^{L}\right)+\theta^{H}+\alpha E(\theta \mid s)=v(0)+\theta^{L}+\alpha E(\theta \mid s)
$$

Canceling out $\alpha E(\theta \mid s)$ from both sides, I obtain

$$
v\left(P^{H} / \theta^{L}\right)+\theta^{H}=v(0)+\theta^{L} .
$$

Note that the college outcome $P^{L}$ and $\underline{P}^{H}$ depend only on which ability types exist in the college. In particular, they do not depend on high school disutility coefficient $\gamma$, networking coefficient $\alpha$, or the share of each ability type within the college. This feature allows me to calculate equilibrium college outcomes only from the equilibrium definitions, and also turns out to be convenient when I prove the existence of equilibrium.

\subsection{Colleges in Asian Equilibrium}

In Asian equilibrium, college A has only high and medium ability types and college B has only medium and low ability types. Firms believe that college A graduates are at least of medium ability regardless of their college performance, because no low ability workers exist in college A. In this separating equilibrium medium ability workers in college $\mathrm{A}$, the lowest ability type in the college, do not study at all $\left(P_{A}^{M}=0\right)$ and get paid their productivity $\theta^{M}+\frac{\alpha}{3}\left(\theta^{M}+2 \theta^{H}\right)$, where $\frac{\alpha}{3}\left(\theta^{M}+2 \theta^{H}\right)$ is the productivity gain from the networking effect.

High ability workers study just enough to weakly separate themselves from medium ability

workers and get paid their true productivity $\theta^{H}+\frac{\alpha}{3}\left(\theta^{M}+2 \theta^{H}\right)$. Their equilibrium performance $P_{A}^{H}$ is thus determined so that medium ability workers are indifferent between their equilibrium 


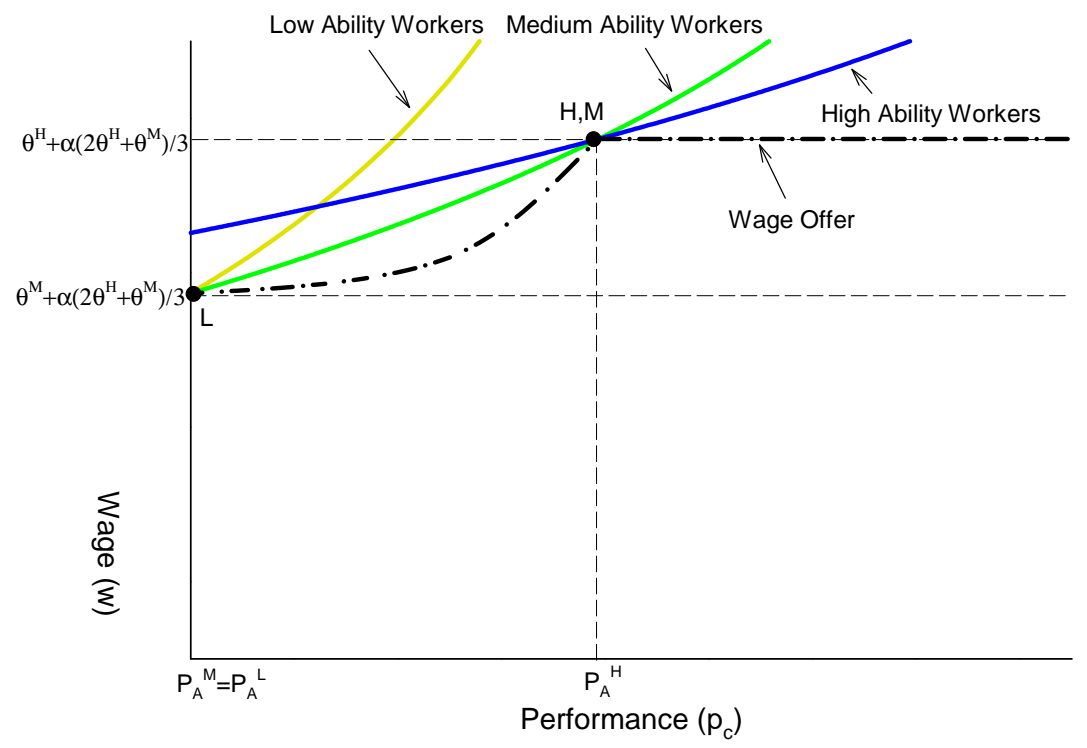

Figure 2: College A in Asian Equilibrium

pay off $\left(0, \theta^{M}+\frac{\alpha}{3}\left(\theta^{M}+2 \theta^{H}\right)\right)$ and the high ability worker's pay off $\left(P_{A}^{H}, \theta^{H}+\frac{\alpha}{3}\left(\theta^{M}+2 \theta^{H}\right)\right)$.

$$
v\left(P_{A}^{H} / \theta^{M}\right)+\theta^{H}=v(0)+\theta^{M}
$$

Even though college A does not have any low ability workers in equilibrium, I still need to know what low ability workers would do in college A because low ability workers compare college A and college B in high school when they decide which college to attend. Low ability workers who graduate from college A would be perceived at least of medium ability because firms believe that any college A graduates are at least of medium ability. Low ability workers in college A would not choose to perform any better than medium ability workers, because it costs low ability workers more effort than medium ability workers to achieve the same level of performance. Since medium ability workers in college A do not study at all, low ability workers in college A would not study at all and get paid the wage of medium ability workers who graduate from college A. 


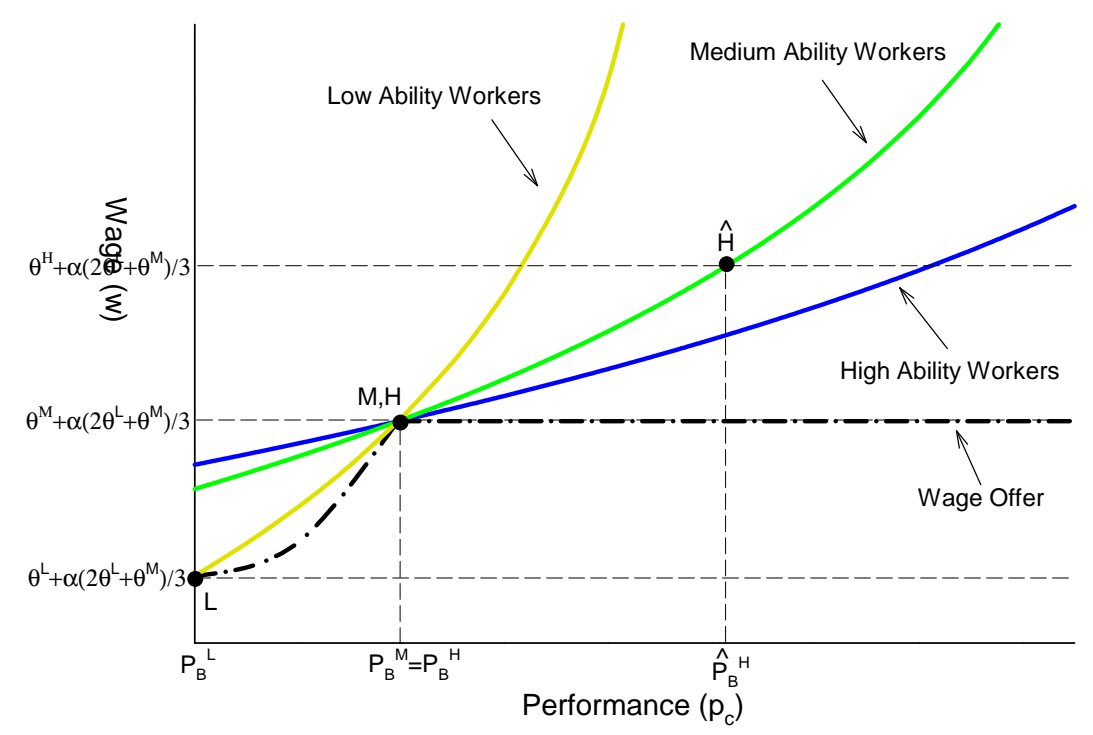

Figure 3: College B in Asian Equilibrium

Figure 2 shows the indifference curves for each ability type in college A and an equilibrium belief of the firms represented by their wage offers. This figure illustrates how each ability type of workers and firms optimize against the others' strategies in college A. Table 1 summarizes the equilibrium outcome in college A.

\begin{tabular}{ccc}
\hline \hline Ability & Performance & Wage \\
\hline Low & 0 & $\theta^{M}+\frac{\alpha}{3}\left(2 \theta^{H}+\theta^{M}\right)$ \\
Medium & 0 & $\theta^{M}+\frac{\alpha}{3}\left(2 \theta^{H}+\theta^{M}\right)$ \\
High & $P_{A}^{H}$ such that $v\left(P_{A}^{H} / \theta^{M}\right)+\theta^{H}=v(0)+\theta^{M}$ & $\theta^{H}+\frac{\alpha}{3}\left(2 \theta^{H}+\theta^{M}\right)$ \\
\hline \hline
\end{tabular}

Table 1: College A in Asian Equilibrium

In college B, there are only low and medium ability workers. In this separating equilibrium, low ability workers do not study at all and medium ability workers study just enough to separate themselves from low ability workers. 
What would high ability workers do if they deviate to college B? High ability workers would not earn more than medium ability workers in college B, because firms believe that any college B graduate is at best of medium ability. Therefore, they do not perform any better than medium ability workers. High ability worker would not perform any worse than medium ability workers either, because it is easier for high ability workers to achieve the same level of performance. Thus, performance and wage of high ability workers in college A are identical to those of medium ability workers. Figure 3 illustrates the equilibrium outcomes in college B, and Table 2 summarizes these outcomes.

\begin{tabular}{ccc}
\hline \hline Ability & Performance & Wage \\
\hline Low & 0 & $\theta^{L}+\frac{\alpha}{3}\left(\theta^{M}+2 \theta^{L}\right)$ \\
Medium & $P_{B}^{M}$ such that $v\left(P_{B}^{M} / \theta^{L}\right)+\theta^{M}=v(0)+\theta^{L}$ & $\theta^{M}+\frac{\alpha}{3}\left(\theta^{M}+2 \theta^{L}\right)$ \\
High & $P_{B}^{H}=P_{B}^{M}$ & $\theta^{M}+\frac{\alpha}{3}\left(\theta^{M}+2 \theta^{L}\right)$ \\
\hline \hline
\end{tabular}

Table 2: College B in Asian Equilibrium

\subsection{Colleges in US Equilibrium}

In US equilibrium each college has all three ability types. Thus, workers of the same ability type perform equally whether they are in college A or college B: low ability workers do not study at all, and the higher ability workers study just enough to separate themselves from the lower ability types. Figure 4 illustrates the college outcomes in US equilibrium and Table 3 summarizes them. Note in this table that college performances $P_{s}^{i}$ do not depend on college name $s$ $(i=H, M, L$ and $s=A, B$.) Therefore, workers having the same ability perform the same level in both colleges. 


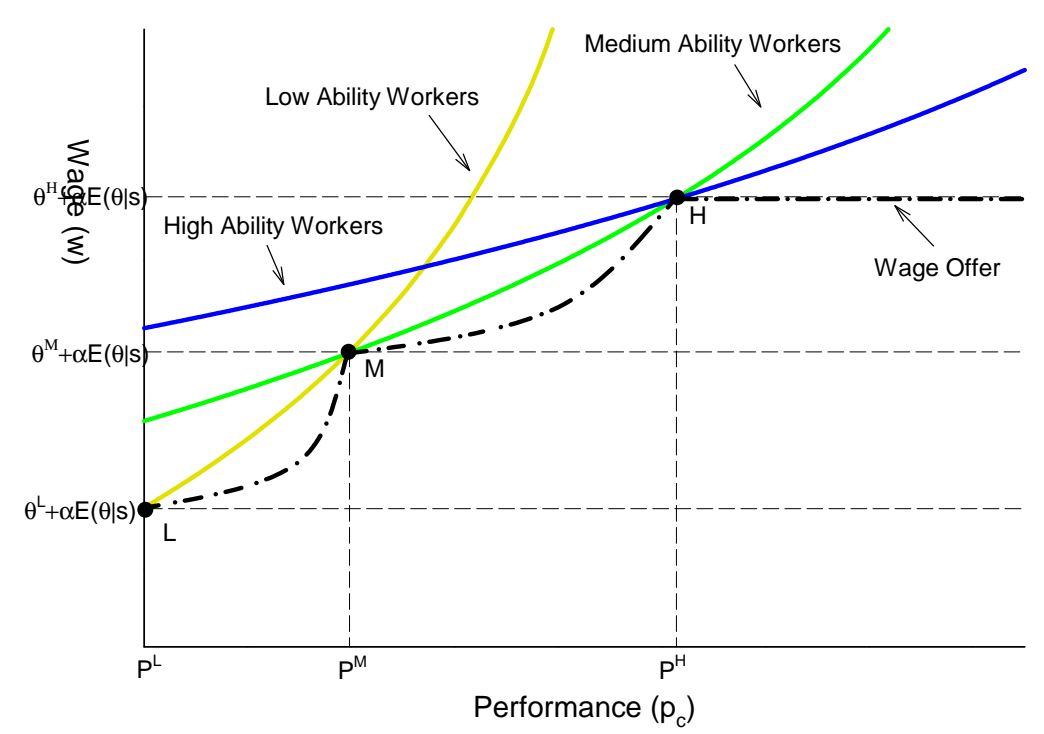

Figure 4: College $s$ in US Equilibrium $(s=A, B)$

\begin{tabular}{ccc}
\hline \hline Ability & Performance & Wage \\
\hline Low & 0 & $\theta^{L}+\alpha E(\theta \mid s)$ \\
Medium & $P_{s}^{M}$ such that $v\left(P_{s}^{M} / \theta^{L}\right)+\theta^{M}=v(0)+\theta^{L}$ & $\theta^{M}+\alpha E(\theta \mid s)$ \\
High & $P_{s}^{H}$ such that $v\left(P_{s}^{H} / \theta^{M}\right)+\theta^{H}=v\left(P_{s}^{M} / \theta^{M}\right)+\theta^{M}$ & $\theta^{H}+\alpha E(\theta \mid s)$ \\
\hline \hline
\end{tabular}

Table 3: College $\mathrm{s}$ in US Equilibrium $(\mathrm{s}=\mathrm{A}, \mathrm{B})$

\subsection{Asian Colleges vs. US Colleges}

In Asian equilibrium any college A graduate is considered at least of medium ability regardless of their college performance, while in US equilibrium college A graduates can be of any ability type. This belief allows college A students in Asian equilibrium to study less in college to signal their ability, thus lowering their college performances. The following result can be easily obtained by comparing Table 1 and Table 2, with Table 3. 
Lemma 3 Every college student performs weakly better in US equilibrium than in Asian equilibrium. In particular, high and medium ability students in college A perform strictly better in US equilibrium.

It follows trivially that college students spend more time studying in US equilibrium because the performance is an increasing function of the study time.

Proposition 1 Every college student spends weakly more time studying in US equilibrium than in Asian equilibrium. In particular, high and medium ability students in college A spend strictly more time studying in US equilibrium.

\subsection{The Benefit of Attending Better College}

In Asian equilibrium, there are two endogenous effects that make college A preferred to college B. First, there is the "networking" effect. The network productivity gain in college A is greater than the productivity gain in college B because the average ability of college A students is higher than that of college B students. Second, there is also a "sorting" effect which makes college A even more attractive. The sorting effect occurs because firms believe that college A graduates are at least of medium ability and college B graduates are at best of medium ability.

In order to better understand this sorting effect, suppose that there is no networking effect $(\alpha=0)$. Low ability workers prefer college A because they can make the medium ability workers' wage by attending college A. Medium ability workers get the same wage whether they attend college A or college B, but still prefer college A because they do not have to study at all in college A. High ability workers prefer college A because they get paid the wage of medium ability workers if they attend college B. ${ }^{3}$ This sorting effect can be verified algebraically by comparing the outcomes in

\footnotetext{
${ }^{3}$ The sorting effect for the high ability type can be shown more rigorously by the following arguments. Comparing the figures 2 and 3 we obtain $\hat{P}_{B}^{H}>P_{A}^{H}$ because medium ability workers are indifferent between $\left(P_{A}^{H}, \theta^{H}\right)$ and $\left(0, \theta^{M}\right)$
} 
Table 1 and Table 2 with holding $\alpha=0$.

In US equilibrium, the sorting effect does not exist. In Table 3 the outcomes for both colleges are identical even if networking effect does not exist $(\alpha=0)$. The networking effect still makes college A weakly preferred to college B, but the size of networking effect is smaller than that of Asian equilibrium because the average students ability difference between college A and B is bigger in Asian equilibrium. Thus the benefit of attending college A is greater in Asian equilibrium ${ }^{4}$.

Proposition 2 The benefit of attending college $A$ is strictly greater in Asian equilibrium than in US equilibrium.

\section{High School and Existence of Equilibrium}

In this section, I study the decision of high school students, such as how much to study and which college to attend. I show that high school students in Asian equilibrium study harder than their counterparts in US equilibrium, and that workers in Asian equilibrium study harder in high school than in college while workers in US equilibrium study harder in college than in high school.

I also derive sufficient conditions for the existence of each equilibrium. Workers' college choices are crucial for existence of equilibrium. For example, in order to show that Asian equilibrium exists, I need to show that no high ability workers choose college B and no low ability workers choose college A. I show that Asian equilibrium exists for sufficiently large networking coefficient $\alpha$ and US equilibrium exists for sufficiently small networking effect coefficient $\alpha$.

I focus on the equilibria where workers' high school performances can be perfectly inferred from

in Figure 2, indifferent between $\left(\hat{P}_{B}^{H}, \theta^{H}\right)$ and $\left(P_{B}^{H}, \theta^{M}\right)$ in Figure 3, but prefer $\left(0, \theta^{M}\right)$ to $\left(P_{B}^{H}, \theta^{M}\right)$. Therefore, high ability workers prefer $\left(P_{A}^{H}, \theta^{H}\right)$ in Figure 2 to $\left(\hat{P}_{B}^{H}, \theta^{H}\right)$ in Figure 3 . It is clear in Figure 3 that high ability workers prefer $\left(\hat{P}_{B}^{H}, \theta^{H}\right)$ to $\left(P_{B}^{H}, \theta^{M}\right)$. Thus, high ability workers prefer the college A pay off $\left(P_{A}^{H}, \theta^{H}\right)$ to the college B pay off $\left(P_{B}^{H}, \theta^{M}\right)$.

${ }^{4}$ The benefit of attending college $\mathrm{A}$ is algebraically defined as $\left\{v\left(n_{c}^{A}\right)+w^{A}\right\}-\left\{v\left(n_{c}^{B}\right)+w^{B}\right\}$, where $n_{c}^{s}$ is the amount of work in college and $w^{s}$ is the wage, if he or she attends college $s(s=A, B$.) 
college names and firms ignore workers' high school performances. Since firms ignore workers' high school performance and thus their wage offers do not depend on high school performance, high school students perform just as much as the cut-off performance for the college they attend. The cut-off performance level $C_{B}$ for college B admission is 0 , because college B is less preferred and there are enough seats in colleges to accommodate all workers. Therefore, only the workers who attend college A would study in high school, working just enough to achieve the college A cut-off performance level $C_{A}$. Note that a worker's high school performance can now be perfectly inferred from his or her college name, which enables firms to safely ignore the redundant signal of high school performance.

\subsection{High School in Asian Equilibrium}

In Asian equilibrium, a half unit measure of medium ability workers attend college $\mathrm{A}$ and the other half unit measure of medium ability workers attend college B. More precisely, medium ability workers with $\gamma<\gamma_{m}$, where $F\left(\gamma_{m}\right)=0.5$, attend college A because they have a lower utility cost of achieving the cut-off performance $C_{A}$ for college A admission, and medium ability worker with $\gamma>\gamma_{m}$ attend college B. Medium ability worker with $\gamma_{m}$ is indifferent between the two colleges, and this uniquely determines college A cut off performance $C_{A}$.

$$
\gamma_{m} v\left(C_{A} / \theta^{M}\right)+v(0)+\frac{\alpha}{3}\left(2 \theta^{H}+\theta^{M}\right)=\gamma_{m} v(0)+v\left(P_{B}^{M} / \theta^{M}\right)+\frac{\alpha}{3}\left(2 \theta^{L}+\theta^{M}\right) .
$$

The above can be rewritten as

$$
\gamma_{m}\left\{v(0)-v\left(C_{A} / \theta^{M}\right)\right\}=v(0)-v\left(P_{B}^{M} / \theta^{M}\right)+\frac{2 \alpha}{3}\left(\theta^{H}-\theta^{L}\right)
$$

The college A cut-off performance level $C_{A}$ also has to satisfy the incentive compatibility condi- 
tions for the other types. In other words, the cut off $C_{A}$ has to be such that no high ability workers deviate to college B and no low ability workers deviate to college A. In order to show that no high ability worker deviates to college B, it suffices to show that the high ability worker with the highest disutility coefficient $\bar{\gamma}$ of studying in high school doesn't deviate to college B. Analogously, I also need to show the low ability worker with $\underline{\gamma}$ doesn't deviate to college A.

Let $\underline{R}_{A}^{L}$ and $\bar{R}_{A}^{H}$ be the maximum high school performance levels which low ability workers with $\underline{\gamma}$ and high ability workers with $\bar{\gamma}$ are willing to achieve in order to attend college A. They are indifferent between attending college $\mathrm{A}$ with these reservation performances in high school and attending college B with 0 performance. Therefore, $\underline{R}_{A}^{L}$ and $\bar{R}_{A}^{H}$ are determined by

$$
\begin{aligned}
& \underline{\gamma}\left\{v(0)-v\left(\underline{R}_{A}^{L} / \theta^{L}\right)\right\}=\theta^{M}-\theta^{L}+\frac{2 \alpha}{3}\left(\theta^{H}-\theta^{L}\right) \\
& \bar{\gamma}\left\{v(0)-v\left(\bar{R}_{A}^{H} / \theta^{H}\right)\right\}=v\left(P_{A}^{H} / \theta^{H}\right)-v\left(P_{B}^{M} / \theta^{H}\right)+\theta^{H}-\theta^{M}+\frac{2 \alpha}{3}\left(\theta^{H}-\theta^{L}\right) .
\end{aligned}
$$

It follows from conditions (1),(2), and (3) that $\underline{R}_{A}^{L}, C_{A}$, and $\bar{R}_{A}^{H}$ converge to $\theta^{L}, \theta^{M}, \theta^{H}$ respectively as $\alpha$ increases to infinity (note that college outcomes $P_{A}^{H}$ and $P_{B}^{M}$ do not depend on $\alpha$ ), which implies that $\underline{R}_{A}^{L}<C_{A}<\bar{R}_{A}^{H}$ for sufficiently large $\alpha$. For these $\alpha$ no low ability workers attend college A and no high ability workers attend college B, and thus there exists an Asian equilibrium.

Proposition 3 There exists an Asian equilibrium for sufficiently large $\alpha$.

The intuition behind proposition 3 is that workers reveal their true ability when the benefit of attending college A is large enough. When the benefit is small, lower ability workers with low $\gamma$ may outperform higher ability workers with high $\gamma$. However, as the benefit becomes larger and larger, all higher ability workers eventually outperform any lower ability worker because they have higher upper bound on their performances. 


\subsection{High School in US Equilibrium}

In US equilibrium, both college A and college B have all three ability types. The heterogeneity in high school study disutility $\gamma$ makes the existence of US equilibrium possible, where some high ability workers with high $\gamma$ attend the inferior college B and some low ability workers with low $\gamma$ attend the superior college A. Therefore, in order for a US equilibrium to exist, the heterogeneity in $\gamma$ has to be sufficiently large relative to the heterogeneity in ability.

Assumption $1 \frac{\bar{\gamma}}{\gamma_{m}}>\frac{\theta^{H}}{\theta^{M}}$ and $\frac{\gamma_{m}}{\underline{\gamma}}>\frac{\theta^{M}}{\theta^{L}}$ where $F\left(\gamma_{m}\right)=0.5$

Unlike Asian equilibrium, the ability distribution of workers across colleges in US equilibrium is not directly pinned down by the equilibrium definition, but has to be endogenously determined. Since the sorting effect is not present in US equilibrium, the networking effect is the entire benefit of attending college A. Workers in high school observe the size of this networking effect and decide which college to attend, aggregately determining the ability distribution of the workers across colleges. This new ability distribution, in turn, determines the size of the new networking effect. In equilibrium, the initial networking effect has to coincide with the resulting networking effect.

When the networking effect coefficient $\alpha>0$ is fixed, the networking effect is determined by the average student ability difference between the colleges. This cross college ability difference $x \equiv E(\theta \mid A)-E(\theta \mid B)$ can not be negative because college A students have better average ability. Further, the cross college ability difference $x$ is smaller than $\frac{2}{3}\left(\theta^{H}-\theta^{L}\right)$ which can be achieved only in Asian equilibrium. Let $\Pi \equiv\left[0, \frac{2}{3}\left(\theta^{H}-\theta^{L}\right)\right]$ denote the set of possible cross ability difference and let $\psi(x): \Pi \rightarrow \Pi$ be the new cross college ability difference correspondence resulting from the workers' college choices, given the initial ability difference $x$.

Suppose $x=0$. There is no networking effect and workers are indifferent between college A and college B. The cut-off performances for admission have to be the same across the colleges, and 
workers randomly choose their colleges. Thus, the new ability distribution of workers is not unique and the resulting ability difference can be any number in $\Pi$, which implies

$$
\psi(0)=\Pi \text {. }
$$

Suppose $x>0$. The cut-off performance for college B admission $C_{B}$ is 0 because college $\mathrm{B}$ is strictly less preferred and the total measure of college admission is equal to the total measure of workers. Given $x$ and $C_{A}>0$, there exists a unique critical disutility coefficient $\tilde{\gamma}^{i}\left(x, C_{A}\right) \in \mathbb{R}_{++}$ for each ability type, such that workers with $\tilde{\gamma}^{i}\left(x, C_{A}\right)$ are indifferent between college $\mathrm{A}$ and college $\mathrm{B}(i=H, M, L)$.

$$
\tilde{\gamma}^{i}\left(x, C_{A}\right) \cdot v\left(C_{A} / \theta^{i}\right)+\alpha E(\theta \mid A)=\tilde{\gamma}^{i}\left(x, C_{A}\right) \cdot v(0)+\alpha E(\theta \mid B) \text { for } x>0, i=H, M, L
$$

Solving above equation for $\tilde{\gamma}^{i}$, I obtain

$$
\tilde{\gamma}^{i}\left(x, C_{A}\right)=\frac{\alpha x}{\left.v(0)-v\left(C_{A} / \theta^{i}\right)\right)} \text { for } x, C_{A}>0, i=H, M, L
$$

Those workers with $\gamma$ lower than $\tilde{\gamma}^{i}\left(x, C_{A}\right)$ for each ability type, attend college $\mathrm{A}$ and the others attend college B. Since college A admits one and a half unit measure of workers, the cut-off performance $C_{A}$ for college $\mathrm{A}$ is uniquely determined by the following condition.

$$
\sum_{i=H, M, L} F\left(\tilde{\gamma}^{i}\left(x, C_{A}\right)\right)=1.5 \text { for } x>0
$$

The above condition implicitly defines $C_{A}$ as a function of $x$. Therefore, $\tilde{\gamma}^{i}\left(x, C_{A}\right)$ also becomes a function of only $x$ and I can write it as $\tilde{\gamma}^{i}(x)$. Since $\tilde{\gamma}^{i}(x)(i=H, M, L)$ pins down the unique ability distribution across the colleges, the cross college ability difference $\psi(x)$ is uniquely 

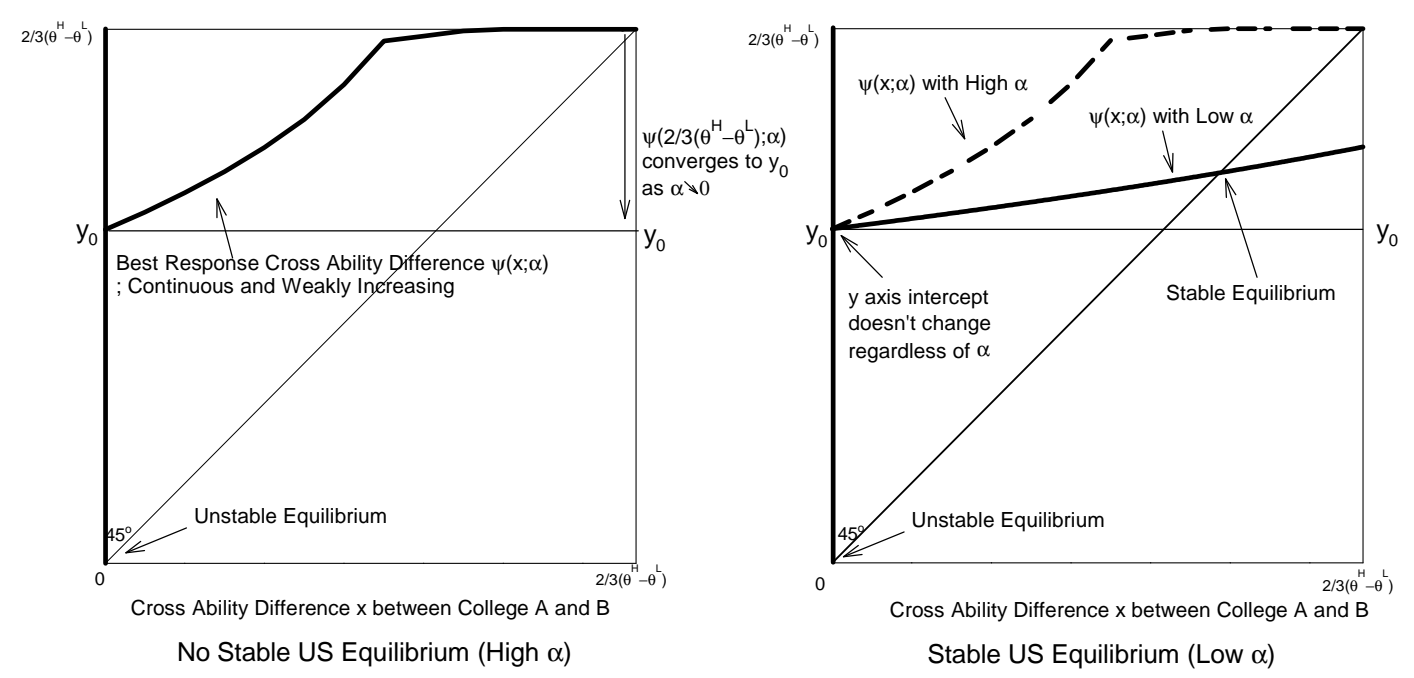

Figure 5: Existence of Stable US Equilibrium and the Networking Effect Coefficient $\alpha$

determined (thus single valued) for $x>0$.

$$
\begin{aligned}
\psi(x) & \equiv E(\theta \mid A, x)-E(\theta \mid B, x) \\
& =\frac{1}{1.5} \sum_{i=H, M, L} \theta^{i} F\left(\tilde{\gamma}^{i}(x)\right)-\frac{1}{1.5} \sum_{i=H, M, L} \theta^{i}\left\{1-F\left(\tilde{\gamma}^{i}(x)\right)\right\} \text { for } x>0 .
\end{aligned}
$$

So far I have assumed that $\alpha$ is fixed when characterizing $\tilde{\gamma}^{i}(x)$ and $\psi(x)$. Since I want to relate $\alpha$ to the existence of US equilibrium, I slightly modify the notations in order to follow the effect of a change in $\alpha$ on $\tilde{\gamma}^{i}(x)$ and $\psi(x)$. Let $\tilde{\gamma}^{i}\left(x ; \alpha^{\prime}\right)$ and $\psi\left(x ; \alpha^{\prime}\right)$ denote $\tilde{\gamma}^{i}(x)$ and $\psi(x)$ with $\alpha=\alpha^{\prime}$ respectively. The following lemma is crucial for analyzing the conditions determining the existence of US equilibrium.

Lemma 4 Let $\underline{\gamma}, \bar{\gamma}, \theta^{H}, \theta^{M}, \theta^{L}$ and $F$ satisfy Assumption 1.

(i) There exists $\gamma_{0}^{i} \in(\underline{\gamma}, \bar{\gamma})$ such that $\lim _{\alpha \searrow 0} \tilde{\gamma}^{i}(x ; \alpha)=\gamma_{0}^{i}$ for all $x>0(i=H, M, L)$.

(ii) For all $\alpha \geq 0$ and $x>0, \psi(x ; \alpha)$ is continuous and weakly increasing in $x$.

(iii) There exists $y_{0} \in\left(0, \frac{2}{3}\left(\theta^{H}-\theta^{L}\right)\right)$ such that $(a) \lim _{x \backslash 0} \psi(x ; \alpha)=y_{0}$ for all $\alpha \geq 0(b) \lim _{\alpha \searrow 0} \psi\left(\frac{2}{3}\left(\theta^{H}-\theta^{L}\right) ; \alpha\right.$ 
$y_{0}$.

Part $(i)$ of Lemma 4 says that each college has all the three ability types (note that $\underline{\gamma}<\gamma_{0}^{i}<\bar{\gamma}$ ) for sufficiently small networking coefficient $\alpha>0$. Part (ii) and (iii) of Lemma 4, illustrated by Figure 5, characterize the graphical properties of $\psi(x ; \alpha)$. Part (iii) of Lemma 4 says that $(a) y$ axis intercept $y_{0}$ of $\psi(x ; \alpha)$ does not depend on $\alpha$ and is strictly between 0 and $\frac{2}{3}\left(\theta^{H}-\theta^{L}\right)$, and that $(b) \psi(x ; \alpha)$ uniformly converges down to a flat line crossing the $\mathrm{y}$ axis intercept (note that $\psi(x ; \alpha)$ is weakly increasing in $x$ due to part $(i i))$.

In a US equilibrium, initial networking effect has to coincide with new networking effect resulting from workers' best response college decisions. Therefore, the following condition has to hold.

$$
x^{*} \in \psi\left(x^{*}\right)
$$

Suppose $x^{*}=0$. Condition (7) is satisfied because $0 \in \Pi=\psi(0)$, and there exists a trivial US equilibrium where all workers are indifferent between both colleges and each worker flips a fair coin between them. In this trivial US equilibrium, each college has the same share of all three ability types. However, this trivial US equilibrium is not stable defined in the following sense.

Definition 4 Denote $x_{n+1} \equiv \psi\left(x_{n}\right)$ for all $n \in \mathbb{N}$. A US equilibrium with the cross ability difference $x^{*}$ is (locally) stable if there exists $\delta>0$ such that $\lim _{n \rightarrow \infty} x_{n}=x^{*}$ for all $x_{0} \in$ $\left(x^{*}-\delta, x^{*}+\delta\right) \cap \Pi$.

Definition 4 is a usual definition of stability, that the system returns to the original equilibrium after small disturbances. The trivial US equilibrium at $x^{*}=0$ is not stable, because $y$ axis intercept $y_{0}$ of $\psi(x ; \alpha)$ is strictly greater than 0 and $\psi(x ; \alpha)$ is continuous and weakly increasing, due to the part $(i i)$ and $(i i i)$ of Lemma 4. 
Suppose $x^{*}>0$. For sufficiently small $\alpha>0$, there exists $x^{*} \in\left(0, \frac{1}{3}\left(\theta^{H}-\theta^{L}\right)\right)$ satisfying condition (7) by the intermediate value theorem because $y$ axis intercept $y_{0}$ is strictly greater than $0, \psi\left(\frac{2}{3}\left(\theta^{H}-\theta^{L}\right) ; \alpha\right)$ converges down to $y_{0}$ as $\alpha$ converges down to 0 , and $\psi(x ; \alpha)$ is continuous, due to the part $(i i)$ and $(i i i)$ of Lemma 4.

Moreover, each college has all the three ability types for sufficiently small $\alpha>0$, due to part $(i)$ of Lemma 4. Therefore, US equilibrium exists for sufficiently small $\alpha>0$. The stability condition is satisfied for at least one US equilibrium because there exists at least one $x^{*}$ where $\psi$ intersects the $45^{\circ}$ line from above and $\psi$ is weakly increasing in $x$.

Proposition 4 Let $\underline{\gamma}, \bar{\gamma}, \theta^{H}, \theta^{M}, \theta^{L}$ and $F$ satisfy Assumption 1. There exists a stable US equilibrium for $\alpha>0$ sufficiently close to 0 .

The intuition behind Proposition 4 is the opposite to that of Proposition 3. Assumption 1 guarantees that low ability workers with $\underline{\gamma}$ outperform the high ability workers with $\bar{\gamma}$ when the benefit of attending college A becomes sufficiently small.

\subsection{Asian High School vs. US High School}

The benefit of attending college $\mathrm{A}$ is greater in Asian equilibrium than in US equilibrium when both equilibria coexist with the same parameters. Therefore, every worker in high school is willing to study more to attend college $\mathrm{A}$ in Asian equilibrium and their cut-off performance for college A admission is higher ${ }^{5}$. Average high school performance is better in Asian equilibrium because high school students perform only as much as the cut-off performance of the colleges they attend.

Lemma 5 Whenever both Asian and US equilibrium coexist with the same parameters, the average performance of high school students is strictly better in Asian equilibrium.

\footnotetext{
${ }^{5}$ If the college A cutoff performance were weakly lower in Asian equilibrium than in US equilibrium, more workers would attend college A than college A can admit.
} 
Now I compare high school performance across US and Asian equilibrium when networking effect coefficients $\alpha$ are different but other parameters are same. Proposition 5 directly follows from Lemma 5 because the benefit of attending college A becomes even larger as the networking effect coefficient $\alpha$ increases.

Proposition 5 Suppose that Asian equilibrium and US equilibrium exist with different networking coefficient $\alpha$ s, and that the networking coefficient $\alpha$ of Asian equilibrium is weakly greater that that of US equilibrium (the other parameters are the same). The Asian equilibrium has strictly better high school performance than the US equilibrium.

These predictions are fairly weak because I expect that Asian equilibrium usually has a better high school performance even when Asian equilibrium has a lower $\alpha$ than US equilibrium. The extreme ability distribution across colleges in Asian equilibrium, which strengthen the networking effect, and the sorting effect that are found only in Asian equilibrium are usually more than enough to compensate the loss in the benefit of attending college A resulting from low $\alpha$.

Rather surprisingly, it is not always true that workers in high school study more in Asian equilibrium even when they have better high school performance. In this model, only those attending college A study in high school. Since workers attending college A in Asian equilibrium have better average abilities than their counterparts in US equilibrium, they need less study time to achieve the same level of performance. It is thus possible that high school students work less in Asian equilibrium even when their performance is better. However, in most cases I expect high school students to work more in Asian equilibrium as will be shown later in simulation section.

\subsection{High School vs. College}

Now I compare study hours between high school and college within each equilibrium. In Asian equilibrium, the benefit of attending college A increases to infinity as networking effect coefficient 
$\alpha$ increases to infinity. Thus, students work harder in high school than in college for sufficiently large $\alpha$. In US equilibrium, the benefit of attending college A converges down to 0 as the networking coefficient $\alpha$ converges down to 0 . Thus, students work harder in college than in high school for sufficiently small $\alpha>0$.

Proposition 6 (i) In Asian equilibrium, students study more in high school than in college for sufficiently large $\alpha$.

(ii) In US equilibrium, students study more in college than in high school for sufficiently small $\alpha>0$.

\section{Simulation}

In this section, I run a simulation varying the networking coefficient $\alpha$. Many theoretical results depend on the size of networking coefficient $\alpha$, and the simulation provides a concrete example illustrating how big or small the coefficient should for each result to hold. I also discuss why we may observe different equilibria across different societies, using the simulation result. Most interestingly, both Asian and US equilibrium may exist under certain conditions. Parameters

used in the simulation are the following: $\theta^{H}=3, \theta^{M}=2, \theta^{L}=1, v(n)=\log (1-n), \gamma \sim$ Uniform $[0.2,0.8]$. The networking effect coefficient $\alpha$ varies from 0 to 0.9 .

Figure 6 summarizes the simulation result. First, note that different equilibria exist with different networking coefficient $\alpha$. Only Asian equilibrium exists for large $\alpha$, and only US equilibrium exists for small $\alpha$. Both equilibria coexist for medium size $\alpha$. Second, Asian students study harder in high school than in college while US students study harder in college than in high school. Moreover, high school students study harder in Asian equilibrium while college students study harder in US equilibrium. This is consistent with the stylized facts. 


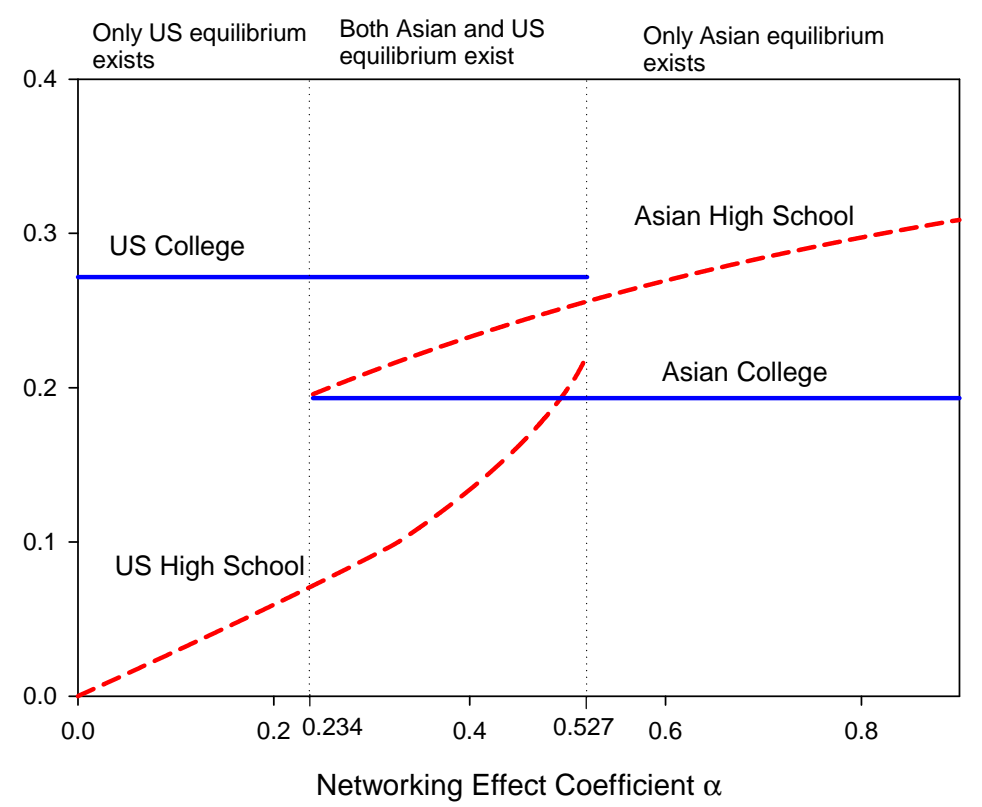

Figure 6: Networking Effect, Existence of Equilibrium, and Study Time

Figure 6 suggests that there are two different kinds of explanations, both consistent with the theory, about why US equilibrium occurs in US and why Asian equilibrium occurs in East Asia. The first explanation is a multiple equilibria argument. Figure 6 shows that both US and Asian equilibrium coexist for medium size $\alpha$. In this case both US and East Asia are interpreted as having the same parameters and the equilibrium is selected based only on the society's self-fulfilling belief. In East Asia, workers study hard in high school because firms believe that college names are better signals of abilities; college names actually become better signals of abilities just because workers compete hard in high school to get into better colleges. In US, workers study hard in college because firms believe that college GPAs are better signals of abilities; college GPAs actually become better signals just because workers compete hard in college to get better GPAs.

The second explanation is that East Asia and US actually have different fundamental parameters, especially the networking effect coefficient $\alpha$. East Asia seems to have higher $\alpha$. Networking has been regarded as one of the most important things to be successful in East Asia. For example, 
in major firms in Japan and Korea there are college alumni associations which promote the success of their members. The alumni connections are considered so important that they have their own names: "Gakubatsu" in Japan and "Hakbul" in Korea.

\section{Empirical Evidence}

This section provides empirical evidence. A testable implication of the theory is that high ability workers in East Asia should be relatively more concentrated among a few top colleges than their counterparts in US. I examine this implication using college distribution data for largest firm CEOs in US and Korea.

The theory claims that college names are better signals of workers' abilities in East Asia than in US. (In the model, Asian equilibrium has only two ability types within each college while US equilibrium has all the three ability types). An immediate implication is that colleges in US should have more heterogeneity among students than colleges in East Asia. Although this conjecture seems quite plausible, this implication is hard to test due to data availability.

An equivalent testable implication is that workers of fixed ability should be more concentrated in a few colleges in East Asia than in US. (In the model, Asian equilibrium has high ability workers only in college A while US equilibrium has high ability workers both in college A and college B). I examine this implication by looking at college distribution of top CEOs for largest firms in US and Korea. Clearly these CEOs are high ability workers and I find that Korean CEOs are substantially more concentrated among a few top colleges as compared with their US counterparts.

Data come from several sources. I look at top CEOs of Standard and Poors 500 firms in US and Hankyung business ranking top 83 firms in Korea. I use 6 times as many US CEOs as Korean CEOs because US is 6 times bigger in population size. I also control for differences in alumni size across colleges, using freshmen enrollment size as its proxy. I obtain 2003 freshmen enrollment data 


\begin{tabular}{|c|l|c|c|}
\hline Ranking & \multicolumn{1}{|c|}{ University } & Number of CEOs & $\begin{array}{c}\text { Cumulative CEO } \\
\text { Percentage }\end{array}$ \\
\hline 1 & Harvard Univ. & 15 & $3 \%$ \\
2 & Univ. of Wisconsin - Madison & 14 & $6 \%$ \\
3 & Princeton Univ. & 10 & $8 \%$ \\
& Stanford Univ. & 10 & $10 \%$ \\
5 & Univ. of Texas - Austin & 8 & $12 \%$ \\
6 & Yale Univ. & 7 & $13 \%$ \\
7 & US Naval Academy & 7 & $15 \%$ \\
& Univ. of Pennsylvania & 7 & $16 \%$ \\
& Univ. of Washington - Seattle & & $17 \%$ \\
\hline
\end{tabular}

(a) US

\begin{tabular}{|c|l|c|c|}
\hline Ranking & \multicolumn{1}{|c|}{ University } & Number of CEOs & $\begin{array}{c}\text { Cumulative CEO } \\
\text { Percentage }\end{array}$ \\
\hline 1 & Seoul National Univ. & 39 & $47 \%$ \\
2 & Korea Univ. & 10 & $59 \%$ \\
& Yonsei Univ. & 10 & $71 \%$ \\
\hline
\end{tabular}

(b) Korea

Table 4: University Ranking in Number of Top CEOs

for each college from National Center for Education Statistics (NCES) and Korea National Center for Education Statistics and Information (KNCESI).

Table 4 shows top US and Korean universities in terms of the number of CEOs among their graduates. It is striking in Korea that Seoul National University alone accounts for 47 percent of the Korean CEOs. Top three colleges in Korea account for as much as 71 percent of the CEOs. On the other hand, top ten US colleges all together account for only 17 percent of the CEOs.

However, Table 4 is misleading for the following two reasons. First, Korea has smaller number of college graduates, and thus universities of the same size would account for bigger share of CEOs in Korea. Second, Korean universities may tend to be bigger in alumni sizes than US universities, and thus each university may account for bigger share of CEOs.

In order to control for these differences, I derive something similar to the Lorenz curve, weighted 


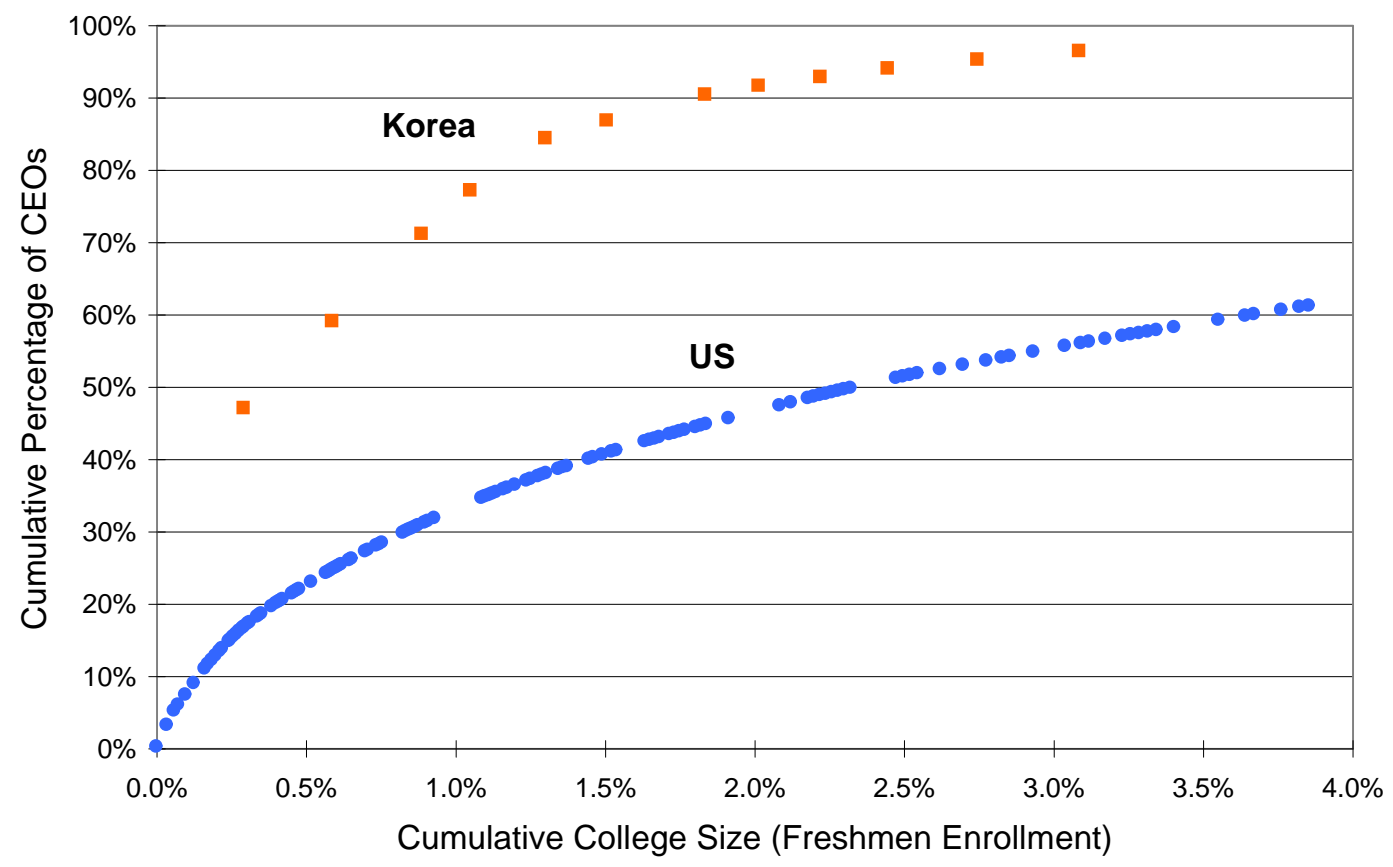

Figure 7: CEO Concentration among Colleges

by school size. First, I calculate per capita number of CEOs by dividing the number of CEOs by year 2003 freshmen enrollment which I use as proxy for alumni size. Second, I rerank schools by the per capita number of CEOs and calculate cumulative percentages of CEOs and alumni size (freshmen enrollment).

Figure 7 shows the result. The figure clearly shows that Korean CEOs are substantially more concentrated among a few top colleges as compared with US CEOs. The curve for Korea is placed uniformly higher than the curve for US. For example, the top university in Korea (Seoul National University), which accounts for only .3 percent of all college graduates, accounts for 47 percent of the CEOs. Top three colleges, which account for less than 1 percent of college graduates, account for more than 70 percent of the CEOs. On the other hand, top .3 percent universities in US account for only 18 percent of the CEOs and top 1 percent colleges account for less than 40 percent. 


\section{Conclusion}

This paper proposes a signaling explanation for the puzzle why American students study more in college than in high school while East Asian students study more in high school than in college. Signaling occurs over time both in high school and in college, and signaling stage may differ across countries. Students work hard in the signaling stage determined by the society as a whole. The model also shows why signaling stage may differ across countries. The signaling stage is likely to be high school if networking is important for job performances. A testable implication of the theory is that East Asia has more concentration of high ability workers among a few top colleges, as compared with US. I confirm this implication using college education data for largest firm top CEOs.

\section{APPENDIX: Proofs of Lemma 1, Lemma 2, and Lemma 4}

\subsection{Proof of Lemma 1}

Proof. Step 1: For all $\left(s^{*}, p_{c}^{*}\right)$ such that a positive measure of workers attend college $s^{*}$ and perform $p_{c}^{*}$ in equilibrium, there exists $w\left(s^{*}, p_{c}^{*}\right) \in \mathbb{R}_{+}$such that $w\left(s^{*}, p_{c}^{*}\right) \equiv w_{1}\left(s^{*}, p_{c}^{*}\right)=w_{2}\left(s^{*}, p_{c}^{*}\right)$. Proof) Suppose to the contrary that $w_{i}\left(s^{*}, p_{c}^{*}\right)>w_{-i}\left(s^{*}, p_{c}^{*}\right)$ for some $i \in\{1,2\}$. Alternative wage schedule $w_{i}^{\prime}: w_{i}^{\prime}\left(s^{*}, p_{c}^{*}\right)=\left(w_{i}\left(s^{*}, p_{c}^{*}\right)+w_{-i}\left(s^{*}, p_{c}^{*}\right)\right) / 2$ and $w_{i}^{\prime}=w_{i}$ elsewhere, is a profitable deviation for firm $i$.

Step 2: For all $\left(s^{*}, p_{c}^{*}\right)$ such that a positive measure of workers attend college $s^{*}$ and perform $p_{c}^{*}$ in equilibrium, it holds that $w\left(s^{*}, p_{c}^{*}\right)=E\left(\theta \mid s^{*}, p_{c}^{*}\right)+\alpha E\left(\theta \mid s^{*}\right)$.

Proof) Suppose that $w\left(s^{*}, p_{c}^{*}\right)>E\left(\theta \mid s^{*}, p_{c}^{*}\right)+\alpha E\left(\theta \mid s^{*}\right)$. An alternative wage schedule $\hat{w}_{1}$ for firm 1 , where $\hat{w}_{1}\left(s^{*}, p_{c}^{*}\right)=\left(w\left(s^{*}, p_{c}^{*}\right)+E\left(\theta \mid s^{*}, p_{c}^{*}\right)+\alpha E\left(\theta \mid s^{*}\right)\right) / 2$ and $\hat{w}_{1}=w$ elsewhere, constitutes a profitable deviation for firm 1. Suppose that $w\left(s^{*}, p_{c}^{*}\right)<E\left(\theta \mid s^{*}, p_{c}^{*}\right)+\alpha E\left(\theta \mid s^{*}\right)$. There exists 
$\varepsilon>0$ such that an a alternative wage schedule $\hat{w}_{1}$ for the firm 1 , where $\hat{w}_{1}\left(s^{*}, p_{c}^{*}\right)=w\left(s^{*}, p_{c}^{*}\right)+\varepsilon$ and $\hat{w}_{1}=w$ elsewhere, constitutes a profitable deviation for firm 1.

\subsection{Proof of Lemma 2}

Proof. Since $v$ is strictly concave, I obtain $\frac{\partial}{\partial \theta}\left(\frac{\partial \hat{U} / \partial p_{c}}{\partial \hat{U} / \partial w}\right)=-\frac{p_{c}}{\theta^{3}} v^{\prime \prime}\left(\frac{p_{c}}{\theta}\right)>0$.

\subsection{Proof of Lemma 4}

Lemma $\mathbf{A} 1(i) C_{A}(x ; \alpha)$ is continuous and increasing in $x$ for all $\alpha>0$, and $C_{A}(x ; \alpha)$ is a continuous and increasing in $\alpha$ for all $x>0$.

(ii) $\lim _{x \backslash 0} C_{A}(x ; \alpha)=0$ for all $\alpha>0$, and $\lim _{\alpha \backslash 0} C_{A}(x ; \alpha)=0$ for all $x>0$.

Proof. (i) $C_{A}$ is uniquely determined by conditions (4) and (5). It follows from condition (4) and (5) that $C_{A}$ is continuous in $x$ because $F$ and $\gamma^{i}\left(x, C_{A}\right)$ are continuous. It is clear from condition (4) that $\gamma^{i}\left(x, C_{A}\right)$ is increasing in $x$ and decreasing in $C_{A}$. In order to satisfy the condition (5), $C_{A}$ has to increase when $x$ increases. Therefore, $C_{A}$ is an increasing in $x$. Similar arguments show that for all $x>0 C_{A}(x ; \alpha)$ is a continuous and increasing function in $\alpha$.

(ii) Suppose that $\lim _{x \backslash 0} C_{A}(x ; \alpha) \neq 0$ for some $\alpha>0$. It follows from condition (4) that $\lim _{x \backslash 0} \tilde{\gamma}^{i}\left(x, C_{A}\right)=0$ for $i=H, M, L$, and therefore $\lim _{x \backslash 0} \sum_{i=H, M, L} F\left(\tilde{\gamma}^{i}\left(x, C_{A}\right)\right)=0$. This is a contradiction to condition (5). Similar arguments show that $\lim _{\alpha \backslash 0} C_{A}(x ; \alpha)=0$ for all $x>0$.

Lemma A 2 For all $\alpha>0$, both $\frac{\tilde{\gamma}^{H}(x ; \alpha)}{\tilde{\gamma}^{M}(x ; \alpha)}$ and $\frac{\tilde{\gamma}^{M}(x ; \alpha)}{\tilde{\gamma}^{L}(x ; \alpha)}$ are increasing in $x$.

Proof. It follows from condition (4) that

$$
\frac{\tilde{\gamma}^{H}(x ; \alpha)}{\tilde{\gamma}^{M}(x ; \alpha)}=\frac{v(0)-v\left(C_{A} / \theta^{M}\right)}{v(0)-v\left(C_{A} / \theta^{H}\right)} .
$$


Therefore, in order to show that $\frac{\tilde{\gamma}^{H}(x ; \alpha)}{\tilde{\gamma}^{M}(x ; \alpha)}$ is increasing in $x$, it suffices to show that $\frac{\left.v(0)-v\left(C_{A} / \theta^{M}\right)\right)}{\left.v(0)-v\left(C_{A} / \theta^{H}\right)\right)}$ is increasing in $C_{A}$, because $C_{A}$ is an increasing function in $x$ due to the part $(i)$ of Lemma A1.

$$
\begin{aligned}
\frac{\partial}{\partial C_{A}} \frac{\left.v(0)-v\left(C_{A} / \theta^{M}\right)\right)}{\left.v(0)-v\left(C_{A} / \theta^{H}\right)\right)} & \left.=\left\{\begin{array}{c}
\left.\left(v(0)-v\left(C_{A} / \theta^{M}\right)\right) \cdot v^{\prime}\left(C_{A} / \theta^{H}\right)\right) \cdot \frac{1}{\theta^{H}} \\
\left.-\left(v(0)-v\left(C_{A} / \theta^{H}\right)\right) \cdot v^{\prime}\left(C_{A} / \theta^{M}\right)\right) \cdot \frac{1}{\theta^{M}}
\end{array}\right\} /\left(v(0)-v\left(C_{A} / \theta^{H}\right)\right)\right)^{2} \\
>0 &
\end{aligned}
$$

The last line comes because $v(0)-v\left(C_{A} / \theta^{H}\right)>v(0)-v\left(C_{A} / \theta^{M}\right)>0, v^{\prime}\left(C_{A} / \theta^{M}\right)<v^{\prime}\left(C_{A} / \theta^{H}\right)<$ $0(\because v$ is concave $)$ and $1 / \theta^{M}>1 / \theta^{H}>0$. Similar arguments show that $\frac{\tilde{\gamma}^{M}(x ; \alpha)}{\tilde{\gamma}^{L}(x ; \alpha)}$ are increasing in $x$.

Lemma A 3 (i) For all $\alpha>0, \lim _{x \backslash 0} \frac{\tilde{\gamma}^{H}(x ; \alpha)}{\tilde{\gamma}^{M}(x ; \alpha)}=\frac{\theta^{H}}{\theta^{M}}$ and $\lim _{x \backslash 0} \frac{\tilde{\gamma}^{M}(x ; \alpha)}{\tilde{\gamma}^{L}(x ; \alpha)}=\frac{\theta^{M}}{\theta^{L}}$.

(ii) For all $x>0, \lim _{\alpha \searrow 0} \frac{\tilde{\gamma}^{H}(x ; \alpha)}{\tilde{\gamma}^{M}(x ; \alpha)}=\frac{\theta^{H}}{\theta^{M}}$ and $\lim _{\alpha \searrow 0} \frac{\tilde{\gamma}^{M}(x ; \alpha)}{\tilde{\gamma}^{L}(x ; \alpha)}=\frac{\theta^{M}}{\theta^{L}}$.

Proof. (i)

$$
\lim _{x \searrow 0} \frac{\tilde{\gamma}^{H}}{\tilde{\gamma}^{M}}=\lim _{C_{A} \searrow 0} \frac{\left.v(0)-v\left(C_{A} / \theta^{M}\right)\right)}{\left.v(0)-v\left(C_{A} / \theta^{H}\right)\right)}=\frac{\theta^{H}}{\theta^{M}}
$$

The first equation comes from condition (4) and Lemma A1. The second equation comes from the l'Hôpital's rule. Similar arguments show $\lim _{x \backslash 0} \tilde{\gamma}^{M} / \tilde{\gamma}^{L}=\theta^{M} / \theta^{L}$. Part $(i i)$ can be proven in the same way.

Lemma A 4 For all $\alpha>0, \lim _{x \backslash 0} \tilde{\gamma}^{L}(x ; \alpha)>\underline{\gamma}$ and $\lim _{x \searrow_{0}} \tilde{\gamma}^{H}(x ; \alpha)<\bar{\gamma}$.

Proof. Suppose that $\lim _{x \backslash 0} \tilde{\gamma}^{L}(x) \leq \underline{\gamma}$. It implies that no low ability workers exist in college A for $x$ near 0 . Since the capacity of college A is 1.5, college A has to have at least half unit measure of medium ability workers. Thus, $\lim _{x \searrow_{0}} \tilde{\gamma}^{M}$ has to be weakly greater than $\gamma_{m}$ where $F\left(\gamma_{m}\right)=0.5$, and I obtain

$$
\lim _{x \searrow 0} \frac{\tilde{\gamma}^{M}(x ; \alpha)}{\tilde{\gamma}^{L}(x ; \alpha)} \geq \frac{\gamma_{m}}{\underline{\gamma}} .
$$


However, using the part $(i)$ of Lemma A3 and Assumption 1 I obtain the following contradicting result.

$$
\lim _{x \searrow 0} \frac{\tilde{\gamma}^{M}(x ; \alpha)}{\tilde{\gamma}^{L}(x ; \alpha)}=\frac{\theta^{M}}{\theta^{L}}<\frac{\gamma_{m}}{\underline{\gamma}} .
$$

Similar arguments show that $\lim _{x \backslash 0} \tilde{\gamma}^{H}(x)<\bar{\gamma}$.

Lemma A 5 There exists $\gamma_{0}^{i} \in(\underline{\gamma}, \bar{\gamma})$ such that $(a) \lim _{x \backslash 0} \tilde{\gamma}^{i}(x ; \alpha)=\gamma_{0}^{i}$ for all $\alpha \geq 0(b)$ $\lim _{\alpha \searrow 0} \tilde{\gamma}^{i}(x ; \alpha)=\gamma_{0}^{i}$ for all $x>0(i=H, M, L$.

Proof. The part $(i)$ of Lemma A3 implies that $\lim _{x \searrow 0} \tilde{\gamma}^{L}(x ; \alpha)<\lim _{x \searrow 0} \tilde{\gamma}^{M}(x ; \alpha)<\lim _{x \backslash 0} \tilde{\gamma}^{H}(x ; \alpha)$ for $\alpha>0$. Therefore, Lemma A4 implies that $\underline{\gamma}<\gamma_{0}^{i} \equiv \lim _{x \backslash 0} \tilde{\gamma}^{i}(x ; \alpha)<\bar{\gamma}$ for $\alpha>0$ $(i=H, M, L$.) Lemma A3 also implies that the limiting ability distribution is identical whether $x$ converges to 0 with $\alpha$ fixed or $\alpha$ converges to 0 with $x$ fixed. Therefore $\lim _{x} \searrow_{0} \tilde{\gamma}^{i}(x ; \alpha)$ with $\alpha>0$ fixed is equal to $\lim _{\alpha \searrow 0} \tilde{\gamma}^{i}(x ; \alpha)$ with $x>0$ fixed $(i=H, M, L$.

\subsubsection{Proof for part $(i)$ of Lemma 4}

Proof. Lemma A5 encompasses the part $(i)$ of Lemma 4.

\subsubsection{Proof for part (ii) of Lemma 4}

Proof. $C_{A}$ is continuous in $x$ according to Lemma A1. I thus obtain from condition (4) that $\tilde{\gamma}^{i}(x ; \alpha)$ is continuous in $x(i=H, M, L$. $)$ It follows from condition (6) that $\psi$ is continuous in $x$. Lemma A2 implies that there will be weakly more higher ability workers in college A relative to lower ability workers as $x$ increases. Therefore, $\psi$ is weakly increasing in $x$.

\subsubsection{Proof for part $(i i i)$ of Lemma 4}

Proof. Part (iii) of Lemma 4 directly follows from Lemma A5. 


\section{References}

[1] Banks, Jeffrey S. and Sobel, Joel. "Equilibrium Selection in Signaling Games." Econometrica, 1987, 55(3), pp. 647-61.

[2] BBC. "Chinese Police Probe Exam Scam." July 11, 2000; Online at http://news.bbc.co.uk/1/hi/world/asia-pacific/829015.stm.

[3] Cho, In-Koo. "Strategic Stability in Repeated Signaling Games," International Journal of Game Theory, 22, 1993: pp. 107-121

[4] Cho, In-Koo and Kreps, David M. "Signaling Games and Stable Equilibria." Quarterly Journal of Economics, 1987, 102(2), pp. 179-221.

[5] Cho, In-Koo and Sobel, Joel. "Strategic Stability and Uniqueness in Signaling Games." Journal of Economic Theory, 1990, 50(2), pp. 381-413.

[6] Elliott, Dorinda. "Learning to Think." Newsweek, September 6, 1999.

[7] Engers, Maxim. "Signalling with Many Signals." Econometrica, 1987, 55(3), pp. 663-74.

[8] Gluck, Caroline. "S Korean Students Face Do-or-Die Exam." BBC, November 6, 2001; Online at http://news.bbc.co.uk/1/hi/world/asia-pacific/1641670.stm.

[9] Hanushek, Eric A. and Luque, Javier A. "Efficiency and Equity in Schools around the World." Economics of Education Review, 2003, 20(4).

[10] Heyneman, Stephen P., and William Loxley. "The Effect of Primary School Quality on Academic Achievement across Twenty-Nine High and Low Income Countries.” American Journal of Sociology, 1983, 88, pp. 1162-94.

[11] Kaya, Ayça "Repeated Signaling Games" University of Iowa working paper. 
[12] Milgrom, Paul and John Roberts. "Limit pricing and entry under incomplete information: An equilibrium analysis." Econometrica, 50:443, 1982.

[13] OECD. Knowledge and Skills for Life: First Results from Pisa 2000. 2001.

[14] Quinzii, Martine and Rochet, Jean-Charles. "Multidimensional Signalling." Journal of Mathematical Economics, 1985, 14(3), pp. 261-84.

[15] Riley, John G. "Competitive Signalling." Journal of Economic Theory, 1975, 10(2), pp. 174-86.

[16] Spence, A. Michael. "Job Market Signaling." Quarterly Journal of Economics, 1973, 87(3), pp. $355-74$.

[17] Woessmann, Ludger. "Schooling Resources, Educational Institutions, and Student Performance: The International Evidence." Kiel Working Paper No. 983, Kiel Institute of World Economics, 2000. 